\title{
The
}

of

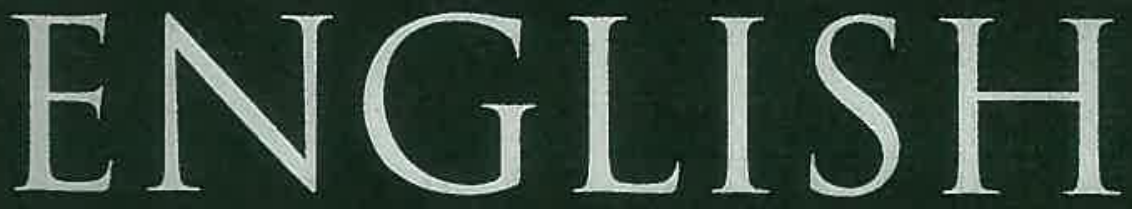

DICTIONARIES

R. M. W. Dixon 


\section{The Unmasking of English Dictionaries}

When we look up a word in a dictionary, we want to know not just its meaning but also its function and the circumstances under which it should be used in preference to words of similar meaning.

Standard dictionaries do not address such matters, treating each word in isolation. R. M. W. Dixon puts forward a new approach to lexicography that involves grouping words into 'semantic sets', to describe what can and cannot be said and providing explanations for this. He provides a critical survey of the evolution of English lexicography from the earliest times, showing how Samuel Johnson's classic treatment has been amended in only minor ways. Written in an easy and accessible style, the book focuses on the rampant plagiarism between lexicographers, on ways of comparing meanings of words, and on the need to link lexicon with grammar. Dixon tells an engrossing story that puts forward a vision for the future.

R. M. W. DIXON is Professor and Deputy Director of the Language and Culture Research Centre at James Cook University, North Queensland and a Fellow of the British Academy. His books include Australian Aboriginal Words in English: Their Origin and Meaning (2nd edition 1995); A Semantic Approach to English Grammar (2nd edition 2005) and Making New Words: Morphological Derivation in English (2014). He is the author of the classic three-volume text Basic Linguistic Theory (20102012) and has published grammars of languages from Amazonia and Fiji, and of several of the original languages of Australia. 


\section{CAMBRIDGE}

Cambridge University Press

978-1-108-42163-8 - The Unmasking of English Dictionaries

R. M. W. Dixon

Frontmatter

More Information

\section{Books by R. M. W. Dixon}

\section{BOOKS ON LINGUISTICS}

Linguistic Science and Logic

What is Language? A New Approach to Linguistic Description The Dyirbal Language of North Queensland

A Grammar of Yidiñ

The Languages of Australia

Where Have All the Adjectives Gone? And Other Essays in Semantics and Syntax

Searching for Aboriginal Languages: Memoirs of a Field Worker

A Grammar of Boumaa Fijian

A New Approach to English Grammar, on Semantic Principles

Words of Our Country: Stories, Place Names and Vocabulary in Yidiny Ergativity

The Rise and Fall of Languages

Australian Languages: Their Nature and Development

The Jarawara Language of Southern Amazonia

A Semantic Approach to English Grammar

Basic Linguistic Theory, Vol. 1, Methodology

Basic Linguistic Theory, Vol. 2, Grammatical Topics

Basic Linguistic Theory, Vol. 3, Further Grammatical Topics I Am a Linguist

Making New Words: Morphological Derivation in English

Edible Gender, Mother-in-law Style and Other Grammatical

Wonders: Studies in Dyirbal, Yidiñ and Warrgamay

Are Some Languages Better than Others?

"We Used to Eat People": Revelations of a Fiji Islands Traditional Village

with Alexandra Y. Aikhenvald

Language at Large: Essays on Syntax and Semantics

with Grace Koch

Dyirbal Song Poetry: The Oral Literature of an Australian

Rainforest People

with Bruce Moore, W. S. Ramson and Mandy Thomas

Australian Aboriginal Words in English: Their Origin and Meaning 


\section{CAMBRIDGE}

Cambridge University Press

978-1-108-42163-8 - The Unmasking of English Dictionaries

R. M. W. Dixon

Frontmatter

More Information

BOOKS ON MUSIC

with John Godrich

Recording the Blues

with John Godrich and Howard Rye

Blues and Gospel Records, 1890-1943

NOVELS (under the name Hosanna Brown)

I Spy, You Die

Death upon a Spear

EDITOR OF BOOKS ON LINGUISTICS

Grammatical Categories in Australian Languages

Studies in Ergativity

with Barry J. Blake

Handbook of Australian Languages, Vols 1-5

with Martin Duwell

The Honey Ant Men's Love Song, and Other Aboriginal Song Poems

Little Eva at Moonlight Creek: Further Aboriginal Song Poems

with Alexandra Y. Aikhenvald

The Amazonian Languages

Changing Valency: Case Studies in Transitivity

Areal Diffusion and Genetic Inheritance: Problems in

Comparative Linguistics

Word: A Cross-linguistic Typology

Studies in Evidentiality

Adjective Classes: A Cross-linguistic Typology

Serial Verb Constructions: A Cross-linguistic Typology

Complementation: A Cross-linguistic Typology

Grammars in Contact: A Cross-linguistic Typology

The Semantics of Clause-linking: A Cross-linguistic Typology

Possession and Ownership: A Cross-linguistic Typology

The Grammar of Knowledge: A Cross-linguistic Typology

The Cambridge Handbook of Linguistic Typology

Commands: A Cross-linguistic Typology

with Alexandra Y. Aikhenvald and Masayuki Onishi

Non-canonical Marking of Subjects and Objects 


\section{CAMBRIDGE}

Cambridge University Press

978-1-108-42163-8 - The Unmasking of English Dictionaries

R. M. W. Dixon

Frontmatter

More Information

\section{The Unmasking of English Dictionaries}

R. M. W. Dixon

Language and Culture Research Centre

James Cook University Australia

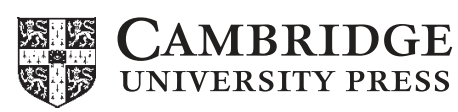




\section{CAMBRIDGE}

\section{Cambridge University Press}

978-1-108-42163-8 - The Unmasking of English Dictionaries

R. M. W. Dixon

Frontmatter

More Information

\section{CAMBRIDGE \\ UNIVERSITY PRESS}

University Printing House, Cambridge CB2 8BS, United Kingdom

One Liberty Plaza, 20th Floor, New York, NY 10006, USA

477 Williamstown Road, Port Melbourne, VIC 3207, Australia

314-321, 3rd Floor, Plot 3, Splendor Forum, Jasola District Centre, New Delhi - 110025, India

79 Anson Road, \#06-04/06, Singapore 079906

Cambridge University Press is part of the University of Cambridge.

It furthers the University's mission by disseminating knowledge in the pursuit of education, learning, and research at the highest international levels of excellence.

www.cambridge.org

Information on this title: www.cambridge.org/9781108421638

DOI: $10.1017 / 9781108377508$

\section{C) R. M. W. Dixon 2018}

This publication is in copyright. Subject to statutory exception and to the provisions of relevant collective licensing agreements, no reproduction of any part may take place without the written permission of Cambridge University Press.

First published 2018

Printed in the United States of America by Sheridan Books, Inc.

A catalogue record for this publication is available from the British Library.

ISBN 978-1-108-42163-8 Hardback

ISBN 978-1-108-43334-1 Paperback

Cambridge University Press has no responsibility for the persistence or accuracy of URLs for external or third-party internet websites referred to in this publication and does not guarantee that any content on such websites is, or will remain, accurate or appropriate. 


\section{Contents}

Abbreviations and Conventions viii

Prologue: The Work in Advance ix

1. How the Language Is Made Up 1

2. What a Dictionary Needs to Do 17

3. Semantic Set: Finish, Cease, and Stop 30

4. Explaining Hard Words 40

5. Putting Everything In 55

6. Semantic Set: Big and Little, Large and Small 71

7. Spreading Wings 87

8. Semantic Organisation 103

9. Semantic Set: Fast, Quick, Rapid, Swift, Slow, and Speed 122

10. No Need to Keep Re-inventing the Wheel 135

11. The Nineteenth Century 146

12. Semantic Set: Want, Wish (For), and Desire 166

13. The Role of Grammar 177

14. Standing Still 194

15. The Way Forward 218

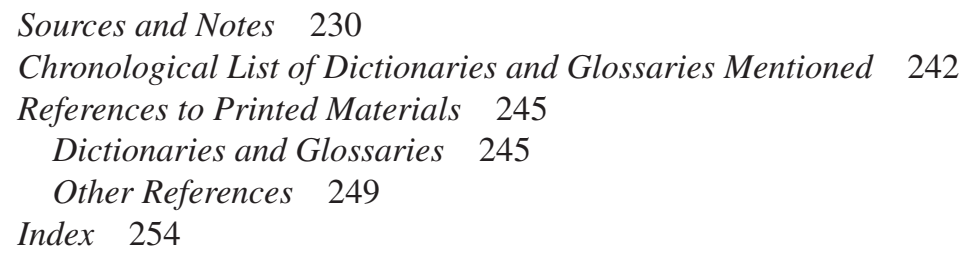




\section{CAMBRIDGE}

Cambridge University Press

978-1-108-42163-8 - The Unmasking of English Dictionaries

R. M. W. Dixon

Frontmatter

More Information

\section{Abbreviations and Conventions}

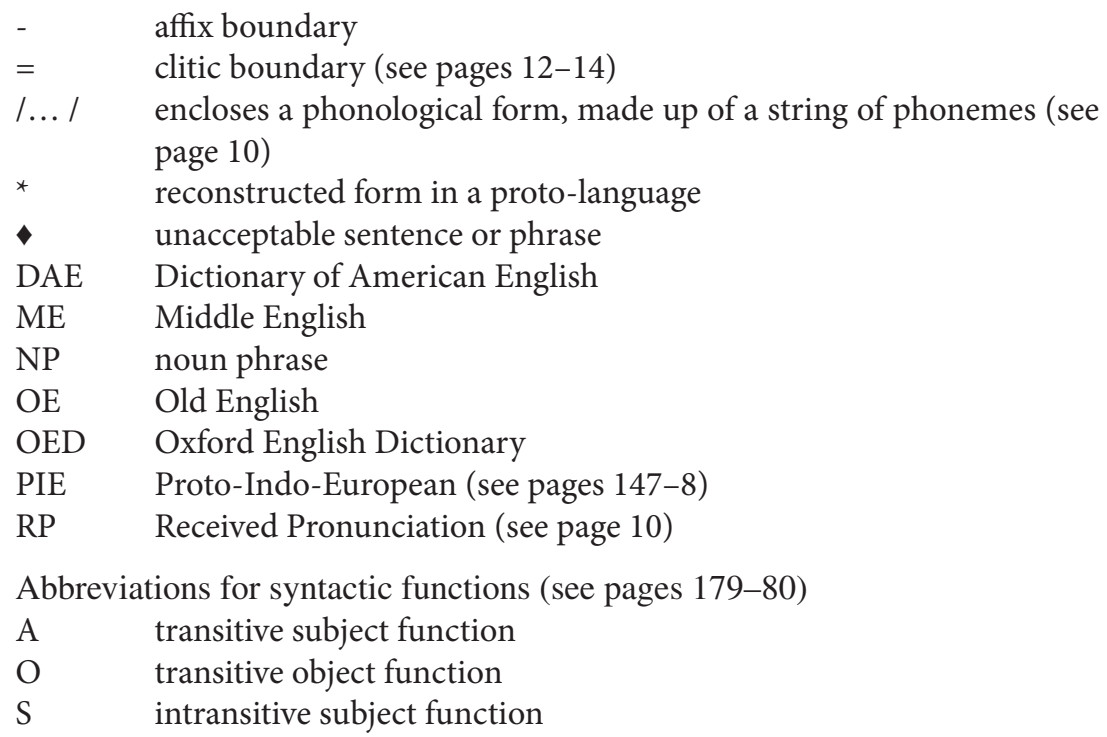

At first mention, dictionaries are generally accorded their full title, in italics; for example, Webster's Ninth New Collegiate Dictionary. Later mentions generally use a shorter form, with no italics: for example, Ninth Collegiate. 
Cambridge University Press

978-1-108-42163-8 - The Unmasking of English Dictionaries

R. M. W. Dixon

Frontmatter

More Information

\section{Prologue: The Work in Advance}

A dictionary should tell you when to use one word rather than another. A word must not be regarded as an isolated item. It is a node in the structural framework of the language.

Towards the end of the first millennium, Anglo-Saxon scholars working with Latin texts would write the Old English equivalent below a Latin word. These 'glosses' were gathered together, and put in order. For the next 500 years they served as the first dictionaries, Latin to English. For each Latin word, an equivalent in English was provided; this was its 'definition'. In 1587 Thomas Thomas gave, for the Latin word lassitüdo, the English meaning wearines (this was one of the spellings used at the time).

The first monolingual English dictionaries - commencing in 1596 - dealt just with 'hard words' (those of foreign origin) and explained them in terms of Germanic forms. The second such dictionary, by Robert Cawdrey in 1604, included:

lassitude, wearines

The Latin head word lassitūdo, in the bilingual dictionary, had been replaced by the cognate English word, lassitude, in Cawdrey's monolingual dictionary. The Romance word lassitude - borrowed into English from French in the middle of the sixteenth century - was 'defined' in terms of adjective weary and suffix -nes(s), which derives an abstract noun (both are of Anglo-Saxon origin).

A bilingual dictionary gives translation equivalents between two languages. A Latin sentence including the word lassitüdo could be translated by an English sentence with wearines. A monolingual dictionary is a quite different matter. It aims to elucidate the meaning of a word (the head word, shown in bold type here) in terms of other words of the same language.

We may get a single word following the head word, as with 'lassitude, wearines'. Does this imply that the words lassitude and weariness have the same meaning, that each could be substituted for the other? Why should we need two words if they mean the same?

In fact, it is never the case that two words have exactly the same meaning. There is always a difference - even if sometimes only slight - concerning what 
they refer to, the circumstances in which they are likely to be used, and the pragmatic effects of their use. The function of a monolingual dictionary should be to discuss and compare words with similar meanings, explaining when to use one and not the other.

Lassitude is a fascinating word, linking physical and mental conditions bodily fatigue on the one hand, and lack of interest or enthusiasm on the other. It has partly overlapping meanings with tiredness and weariness, and also with langour and lethargy. In order to know when to use lassitude, rather than a word of related sense, a dictionary user should be able to consult an account of the similarities and differences of meaning between lassitude and its congeners, their grammatical possibilities, and the interpersonal consequences of selecting one word over another.

By and large, the dictionaries we have today fail to provide this information. In the present book, I will show that this is due to a misconceived methodology. Developing and refining the principles of 'glossing', from a thousand and more years ago, has led to the idea that the meaning of a word - considered as a discrete figment - can be adequately rendered by a 'definition'. In some circumstances, it is suggested that the definition could be substituted for the head word in a sentence, with no significant shift in meaning.

Treating each word as a self-contained entity is the FIRST of three radical faults afflicting present-day lexicography. Each word must be placed within its semantic milieu, the set of words with related meanings. And each such set must be located within the interlocking framework of the entire vocabulary. Words must also be linked to grammar; different nuances of meaning may imply different structural possibilities (and vice versa).

For example, want and wish have compatible meanings; one can say either $I$ wish to apply for that position or I want to apply for that position. But, alongside I wish that I had applied for that position, it is not permissible to say $\downarrow$ want that I had applied for that position. The grammatical possibilities correlate with meaning differences, and this must be brought out in a dictionary. (Want, wish (for), and desire are discussed in chapter 12.)

Finish and cease both relate to something which was - but no longer is happening. One can say either That bank ceased trading last June or That bank ceased to trade last June. However, with finish only the first alternative is possible - That bank finished trading last June but not $\downarrow$ That bank finished to trade last June. This grammatical difference reflects a fundamental contrast in meaning for the two verbs. (Chapter 3 has a fullish discussion of cease, finish, and their congeners.)

Lexical meaning and grammatical properties are intertwined; each helping to characterise the other. Grammar cannot be properly studied without close attention to the semantic proclivities of grammatical slots, and the kinds of lexical words which may fill them. Contrariwise, the contrastive meanings of 
words (from a certain semantic set) determine their grammatical functions. Each grammatical construction carries a meaning, and each lexical word has a meaning; these will combine together to show what can be said, and why.

We began by stating that a dictionary should assist the reader in deciding when to use one word rather than another. This aim cannot be achieved through just a list of lexical words, generally in alphabetical order, with a short 'definition' provided for each (and an indication of whether the word is a noun, verb, adjective, or whatever). Lexicon and grammar are interlocking facets of language. In order to learn how to speak and understand a language, equal consideration must be paid to these two components, and to their semantic linkages. Not paying anything like adequate attention to grammar constitutes the SECOND major failing of present-day lexicography.

We can loop back to the early monolingual dictionaries. In the seventeenth century, the head words were forms which had been borrowed from French and Latin during the previous couple of centuries. They were defined in terms of a quite different set of words, those inherited from Old English (plus a few words taken over in the Middle Ages from other Germanic tongues). At that time, the purpose of a dictionary was to explain 'hard words'.

At the beginning of the eighteenth century, the concept expanded. A dictionary should now cover all words in the language, even common adjectives such as little and small. That is, Germanic words were now included, and they were defined in terms of ... well, in terms of other Germanic words. Nathan Bailey's dictionary from 1730 was the best of its era. But some definitions for the most frequent words were not really very helpful. For example:

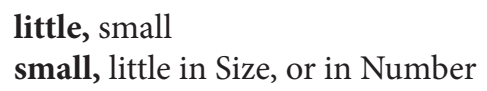

Little and small may be used interchangeably in some contexts, but by no means in all. In Bailey's time, as today, little sister meant younger sister (irrespective of size). One may say, Only a little snow fell last night. Small is not permissible here. On the other side of the coin, only small may be used in The dresses were all of a small size and Only a small number of people were killed in the avalanche. (Chapter 6 deals with little and small plus, of course, big and large.)

Beside being only partial, these two entries of Bailey's are uninformative. If the reader was already familiar with one of the words little and small, they would get a rough idea of the meaning of the other. If they knew neither, they would simply be bewildered.

Things haven't improved all that much over the centuries. A large modern dictionary lists the following lead senses:

choose, select out of a greater number

select, choose, esp. as the best or most suitable 
Cambridge University Press

978-1-108-42163-8 - The Unmasking of English Dictionaries

R. M. W. Dixon

Frontmatter

More Information

Select, taken from Latin in the latter part of the sixteenth century, and the Anglo-Saxon word choose are here defined in terms of each other.

What the reader needs - to be able to decide what to use when - is explicit comparison of the meanings and functions of the words. Choose has a wide general meaning, whereas select is a hyponym of it. That is, the meaning of select is included within that of choose. In virtually every instance, select can be replaced by choose; for example, They selected/chose the films to be shown at the festival. However, there are many uses of choose where select would not be possible. For instance, when followed by between, as in: She couldn't choose between the diamond ring and the ruby earrings. And only choose can take a то complement clause, as in: She chose to close the meeting early.

Suppose that a foreign learner wanted to know how to use the verb ask, and consulted a medium-sized dictionary from the mid-twentieth century. The trail of enquiry goes:

ask, call for an answer to

answer, reply to

reply, make answer, respond, in word or action (to)

respond, make answer (especially of congregation making set answers to priest, etc.); perform answering or corresponding action

The entry for ask refers the learner to answer. That leads to reply, which bounces back to answer; but it also mentions respond. However, the respond entry scarcely helps, simply circling back to answer.

If every word can be defined in terms of every other word, where to start and where to stop? One solution would be to recognise a small set of 'basic words' which would not themselves be defined but could be used in the definitions of non-basic words. The definitions would of course have to be succinct, and not umpteen lines long. In the mid-twentieth century there were a handful of dictionaries which adopted a 'defining vocabulary' of 1,500 to 2,000 words; all other words were defined in terms of these. However, words on the defining vocabulary were also accorded definitions and these showed the same old circularity (see pages 204-10).

We mentioned the recurrent suggestion that, in many circumstances, a definition should be substitutable in a sentence for its head word, with no significant shift in meaning. This is sometimes feasible. For example:

widow, woman who has lost her husband by death and has not married again

In place of Maria is a widow, one could say, Maria is a woman who has lost her husband by death and has not married again. However, this doesn't extend 
very far. When our foreign learner hears Little Jimmy has a new dog and wishes to know what this is, they look up the dictionary:

$\mathbf{d o g}$, any four-legged flesh-eating animal of the genus Canis, of many breeds domesticated and wild, kept as pets or for work or sport

The entry is encyclopaedic and instructive, but it can not be substituted into Little Jimmy has a new -. As another instance, the definition call for an answer to is not substitutable for head word ask in, for example, Tom asked Bill for a cigarette or Robin asked Hilary to come to the party. The same applies for most of the definitions quoted in this volume. I am not suggesting that a definition should be substitutable for its head word, but am simply pointing out that this is something which has often been suggested, and that it only occasionally succeeds.

Whether a definition is substitutable or not is a minor matter, something of a distraction. The main point at issue is that, in all modern-day dictionaries, definitions are haphazard, unsystematic and unprincipled. Anything is defined in terms of anything else, and - as with the ask and answer example - it often leads round in a circle, taking you back to where you started, and not much wiser for the journey.

Relying on definitions is the THIRD shortcoming of present-day lexicography. This ties in with the first one, dealing with each word as an autonomous entity. The way a word is used can only adequately be explained - and understood - by placing it within its semantic and grammatical homeland. This involves matching it against words with similar and opposite meanings, and examining the contexts in which each of these may be used, with well-chosen examples illustrating semantic nuances and subtleties. There will be links from one semantic set to others, and from one grammatical configuration to a related one.

A few years ago, a leading lexicographer explained his plan of attack for a new dictionary - 'Letters A and B will be my responsibility, Ivan will do C, Vanessa D and E, and then I'll chip in again with F, G and H.' A better plan would have been for one person to deal with verbs of motion, another with verbs of speaking, a third with value adjectives, and so on. A set of similar words (for example, lovely, beautiful, pretty, handsome, and the like) should be the province of a single lexicographer, who would examine the contrasts between them. As a final step, the entries could be collated into a single alphabetical listing, to make a conventional dictionary.

Constraints on dictionary-making include time, expertise, money (to pay for the time and expertise) and size. As a book, a dictionary has to be of a size that can be afforded and easily used. Space is always at a premium. Each entry is a compromise between informativeness and succinctness.

However, the world has moved on. Computers can accomplish complex tasks in no time at all. During the last few decades, they have been of immense 
Cambridge University Press

978-1-108-42163-8 - The Unmasking of English Dictionaries

R. M. W. Dixon

Frontmatter

More Information

help to lexicographers in compiling and searching corpuses, laying down a foundation on which definitions are based.

With computers, space limitations dissolve. Things need no longer be presented as a list, in a single dimension. The semantic and grammatical superstructure which characterises a language can be encoded as a multi-dimensional matrix.

Open the 'dictionary file' on your computer, and enter little. You will be directed to the semantic set centred on big and little, large and small (see chapter 6). There will be sidelinks to sets dealing with short, long, and tall; deep and shallow; wide and narrow; and more besides.

There will be characterisation of the words in a semantic set within an overall conceptual template, comparing and contrasting them in terms of structural frames and pragmatic implications. No 'definitions', in the traditional sense; no round-in-a-circle peregrinations.

The plan of this volume is as follows. First, there are chapters on 'How the language is made up' and 'What a dictionary needs to do'. There follows a narrative on the evolution of English dictionaries, step by step - from the early glossing, through dictionaries of 'hard words' to those which dealt with all words (including, inappropriately, grammatical elements such as the and this). The historical account is interwoven with discussion of types of semantic organisation; with the tradition of copying or part-copying from predecessors (often held to be the only suitable methodology), and with the role of grammar.

Dictionaries came of age with Samuel Johnson, distinguishing different senses of words and including illustrative examples 'from the best writers'. Johnson's methodology underpinned the massive and magisterial Oxford English Dictionary, which commenced at the end of the nineteenth century. But then progress halted. During the last century, dictionary-making has been virtually untouched by the emerging science of linguistics. Advances in the understanding of semantics and grammar stand apart, not considered relevant for the grand old tradition of lexicography (treated almost like a branch of history).

Interspersed within the general story are preliminary accounts of four semantic sets - that including finish, cease, and stop in chapter 3; big and little, large and small in chapter 6; fast, quick, rapid, swift, slow, and speed in chapter 9; and want, wish (for), and desire in chapter 12.

The final chapter recapitulates proposals made throughout the book, setting out the blueprint for an innovative - and, indeed, revolutionary - approach to dictionary-making. 